\title{
Research on the Pragmatics of Politeness Principle of Bulletin Board System based on the Differences of Gender and Habits
}

\author{
Guojun $\mathrm{Li}^{1}$ \\ ${ }^{1}$ Baise University, Baise, \\ Guangxi Zhuang Autonomous Region, \\ 533000 China
}

\begin{abstract}
In this paper, we conduct research on the pragmatics of politeness principle of bulletin board system based on the differences of gender and habits. The openness of the Internet makes all kinds of information received into the vision of an equal chance and web sites in order to improve the hit rate which causes the traffic of commercial purposes such as tabloidization tend to be more negative news spread. To strengthen the research of network language management strategy, it has very important theoretical significance and practical meaning analyzed. Our proposed methodology will help researchers to understand the approaches to use the pragmatics of politeness.
\end{abstract}

Keywords: Bulletin Board System (BBS); Politeness Principle; Gender and Habits.

\section{Introduction}

Politeness as a social phenomenon has been attracting the attention of people. Some people say that began since the existence of human communication. Historically, the communication between people cannot live without communication. With the rapid and bursting development of science and technology, communication became more varied and more convenient, fast and frequent. Along with the rapid development of Internet and increasing the number of Internet users, Internet language in people's social language life provides many advantages at the same time, also appeared a lot of language anomie phenomenon, such as wrong character phenomenon, the phenomenon of new words, negative phenomena such as content, in part to the current language teaching in China, the popularization of standard Chinese have considerable impact, and cause the extensive concern of the society from all walks of life. To strengthen the research of network language management strategy, it has very important theoretical significance and practical meaning analyzed. If we think the language itself manners between users of the language and politeness are equal, so just touched the polite to the surface of the problem. In human communication, the party has need polite expression desire, the other party to the polite words and sentences react accordingly. While the expression of politeness will affect the communication between the speaker and the listener effect, and the role of the communication effects and affect the speaker polite intention expression which will complicating communicative situation. In real life, the speaker or because of the face, or out of strategy, often the true intentions hidden, let others to understand from the word meaning, this is another big characteristic of human verbal communication. So understanding speech intention has become an important subject to understand and explain the meaning of the word. The standardization and the rationality of the network language, network language influence on Chinese vocabulary and impact on the current focus on the more are the network language word formation and its resolution. Studies of network language focus on changes in angle, illustrates the social also to network language specification and acceptance process. Network language not only in daily communication, including Internet users and network media use of vocabulary, also including phrases and sentence patterns [1]. 
In view of the network language management problems, scholars from different angles discuss the principles and measures of management which could be summarized as the flows. (1) Hierarchical said. Hold this view of scholars believe that, because of the network language and language use main body acceptable degrees have hierarchy, so the network language specification and management should be level. (2) Let say. Some scholars also put forward for the development of network language don't have to intervene, can drift along development, with netizens use the Internet language, there must be some language preserved, added to the category of social common language, is bound to be some don't adapt to the development of the society factors natural death. (3) Harmonic said. Hold this view of scholars think that due to the particularity of the network language has its existence, the management of the network language and specification should be different from the management of social common language and specification, there is a very different measure of both. So tolerance, understanding and the unreasonable factors exist in the network language, and guide, with a positive attitude to recommend to more effectively the network language and specifications [2-3].

In this paper, we conduct research on the pragmatics of politeness principle of bulletin board system based on the differences of gender and habits. Communication is a basic phenomenon of human society which is a kind of human interaction and contact way. It is a different time or space between the cognitive subjects on the process of mutual exchange of information. Language is human society's most basic tool of communication. New network communication environment and unique mode of transmission, make network language with its unique personality. Network language is the people on the Internet are widely used in the information communication between a set of information symbols. In the following sections, we will introduce our methodology in detail.

\section{The Proposed Methodology}

The Characteristics in the Process of Network Language. The immediacy of network information communication requirements in the shortest time the largest amount of information and efficiency is a feature of the network language is very important, so the network language has a large number of thumbnails. Convenient in Chinese on the input mode is less than English, by contrast, some digital sign letters of inputting more convenient. Network language also try to break through the limitations of the original written symbols, change the language of certain words form significance of conventional, created a new form of significance, and by these simple symbols convey thoughts and feelings of the rich connotation, the information exchange of valuable time. In order to improve the exchange rate, netizens seldom use complex sentences and ellipsis phenomenon is very common, which reflects the characteristics of network language economy. Visible, the network language the biggest characteristic is its simplicity, letters and symbols can be real and vivid to express complicated ideas, which adapted to the fast pace of network information communication, realize the interaction of many exchanges of information, it also saves time and cost, improve the efficiency of information exchange. Network language belongs to the buzzwords, cycle has certain popularity. The instability of the network language is embodied in the frequent replacement. Popular online may, therefore, with the growth of a new generation of Internet users and joining and out of fashion, some will be slowly washed out, such as passing. Any rich individual character and the ability of netizens could this network popular language, greatly accelerated the speed of network language. On the other hand, the network language is mainly popular in the younger generation and they like to pursuit of novelty and further accelerate the speed of network language update frequency. 
Similar and different places have different dialect and the network language also has its regional. But the regional more based on virtual community communication subject line. Therefore, the network language study cannot leave the virtual community. Network language in the network BBS or more flourish, a broader spread, transmission speed faster. We have seen the popularity of network language is generally integrated vocabulary. Some network language even in a particular type of virtual community is very popular, and in another type of virtual community there is none that knows. Deeply the influence of network language to us, to the universities' ideological and political education work brings opportunities also poses a challenge, a study of the causes of cyber language was popular among college students, as well as the positive and negative influence on college students, and the advantage of the characteristics of network language itself and the value of education, to explore the corresponding education countermeasures, in view of the advantages and disadvantages for college moral education to the better use of network resources to provide advice and reference, in theory for the research of college ideological and political education work conform to the changes in the network information age to provide support. The debug function of network society and the use of the characteristics of network language will promote the development of the public's mental health. Also has some characteristics of the real society, network society of the positive factors in the network language can develop the mass communication ability, innovation ability as well as providing the view, expressing emotions, promote the development of mental health of the masses [4].

The Pragmatics of Politeness Principle. The openness of the Internet makes all kinds of information received into the vision of an equal chance, and web sites in order to improve the hit rate, the traffic of commercial purposes such as tabloidization tend to be more negative news spread. Some scholars according to different contents of network bad information is divided into yellow pornographic information, red bloody violence hatred, grey black false information and negative reactionary information illegally. Because of the need for "feeling" is the human language, in social communication constantly perfected a set of symbol system. So with words of language symbols, whether spoken or written, must have the intention, it is to know the word meaning must grasp the first point. When words meaning was completely consistent with the literal meaning, also have what intention, mostly appear in the context of a reckless. But in more cases, the intention is always hidden deep in the meaning beyond the literal meaning of words. People use language to express their own thoughts, but sometimes people expressed by the sentences are not necessarily really want to express the intention of the speaker, because language can mask the speaker's real thoughts and intentions. Also, people can use language to express politeness, but also will hide the speaker's politeness language. Therefore, if you need to correctly understand the intention of the speaker, correct understanding of politeness, we will not be able to focus solely on the structure of the language.

In language communication, the speaker and the audience, as well as others, but whether the language politeness and is not determined by the speaker, but decided by obedient and other audiences. So the polite language communication is not determined by the language attribute, the form or content of polite language for hearer may be polite, may also have no manners. But most of the time, people can not only evaluate whether language communication manners and meaning or sentence depends on the surface meaning. Need the hearer often goes beyond the conventional meaning or literal meaning of the language to understand the speaker to convey the real communicative meaning, to judge the speaker discourse polite or impolite. So, to really read the speaker's communicative purpose and 
intention is our general evaluation of the important factors of politeness. From this perspective, are polite effects, and the interpretation of linguistic politeness interpretation process is actually a mental process. Literal politeness in language communication is only a means of expression, the speaker and practical politeness is the real purpose of speakers who want to express. So when interpreting communicative language, we should from the psychological and emotional aspects of the speaker to see polite questions, including the speaker's purpose and intention, but also contains the hearer to hear words of understanding.

The Politeness Principle based on Gender and Habits. Network language management strategy is based on the development of network language situation and management measures. Parsing the connotation of the network language management strategy it is necessary to define the connotation of network language and the connotation of the network language management. Network language, as a new concept category has broad sense and narrow sense, the establishment of its connotation and denotation, different people have different standards. The generalized network language is refers to in the network transmission applications or touches all languages, including humans natural language and physical technology. The former is used for the realization of interpersonal communication and the exchange of language. The latter is in order to guarantee the normal operation of the network media and the development of innovation and the use of technical language. Narrow sense of network language is refers to people on the Internet for information collection, distribution and exchange the use of natural language, it is the most popular clear and convenient directly terminal information symbols. Chinese netizens showed the following characteristics. (1) Better educated. Most of China's Internet users have the record of formal schooling of above of middle school, they can use or more proficient use of English and computer, this is the network language that can be filled with many new words, mixed Chinese and English vocabulary and the possibility of interesting Numbers and symbols. Have certain cultural level of the Internet is full of wisdom and vitality, like wit and easy communication and they pursue the humorous language style. (2) More practical. Pragmatism and postmodern deconstruction is one of the important schools of thought in the world today. Under the influence of pragmatism ideas, people pay more attention to the pursuit of "useful" and "simple". Young people are Internet users in the main body, is keen to chase fashion. They carried on the bold reform to the traditional language, created along with the gender and simplicity of network language. (3) Younger. China's Internet users are mostly young people under the age of 30 and young people thinking active, curious, individual character make public, eager to communicate and advocating innovation, the pursuit of fashion, and not willing to suffer in real life too many constraints, normative constraints include the mainstream language. In order to make public individual character, selfexpression, they try to be unique to create a new language is different from the traditional language system, as their communication tool on the Internet. (4) Has the characteristics of unique personality. In this information era of rapid transmission network, already has a considerable important position of the network language. (5) Has the characteristics of easy to set. Simple text emoticons English letters can use comprehensive words and figures such as language express all kinds of feelings and thoughts in the combination of the most convenient and easy to enter remote network language cannot be restricted by the language combination rules of the net can be fully free combination and mix away this is the characteristics of network language easy to set.

On appropriating the characteristics of network language is also a variety of views from some experts to explore language speaking with 
instability and informality there are also some experts put forward the network language so vulgar directly review here today also can't fully summarized the characteristics of network language but all features of network language as a new language has largely changed our lives we should pay more attention to its active learning and generalization contribute to the development of our social life good positive energy.

\section{Conclusion}

In this paper, we conduct research on the pragmatics of politeness principle of bulletin board system based on the differences of gender and habits. Network language style and the speech style is the complex system in real life, realistic style contains all kinds of style category is still exists in the network. Because Internet interaction is strong, pay attention to site and the relationship between the user, to strengthen the communication between the user and support public comments, striving for equality, freedom of virtual community, so the network speech has a tendency toward life, even the use of computer software tutorial, tend to present the characteristics of the integration of scientific style and the style of conversation. Everything and close to the content and values of the people decided the main style of conversation style for the network speech. In conclusion, through our research, we could build up better Internet chatting atmosphere in the future.

\section{References}

[1] Nielsen J B, Graff C, Rasmussen P V, et al. Risk prediction of cardiovascular death based on the QTc interval: evaluating age and gender differences in a large primary care population. $[\mathrm{J}]$. European.

[2] Wang X M, Zhang Z M. Taiwan People's Gender Role Attitudes and the Cohort Differences:Based on dynamic data bank of Chinese household[J]. Journal of Fujian Jiangxia.

[3] Nicu Ionel Sava, Adrian Cristian Papari. Comparative Study on the Phenomenon of Suicide Based on Gender and Season [J]. Procedia - Social and Behavioral Sciences, 2015:532 - 535 .

[4] Fein O, Yeari M, Giora R. On the priority of salience-based interpretations: The case of sarcastic irony[J]. Intercultural Pragmatics, 2015 , 